\title{
CONF-850504--284
}

2

UCRL- 91914

PREPRINT

BHosen: OCTO1 1985

\section{BRIGHTNESS MEASUREMENTS ON THE LIVERMORE \\ HIGH BRIGHTNESS TEST STAND}

G. J. Caporaso and D. L. Birx

This paper was prepared for submittal to the 1985 Particle Accelerator Conference

Vancouver, B. C., Canada

May $13-16,1985$

May 9, 1985

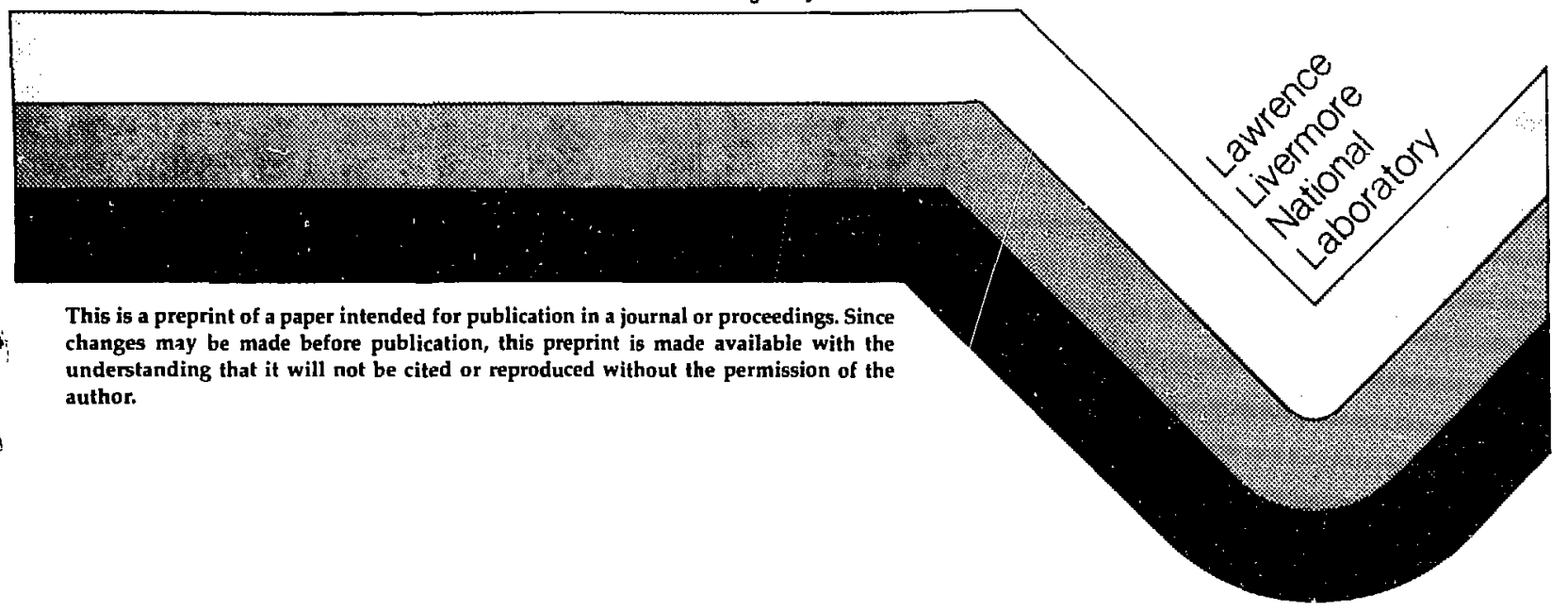

DASTABBUTLOY OF THIS DOCJMEET IS LALUMTED 


\title{
BRIGHTNESS MEASUREMENTS ON THE LIVERMORE
}

\author{
HIGH BRIGHTNESS TEST STAND*
}

\author{
G. J. Caporaso and D. L. Birx \\ Lawrence Livermore National Laboratory \\ University of California \\ Livermore, California 94550
}

May 9,1985

UCRL--91914

ABSTRACT

DE86 000016

Several techniques using small radius collimating pipes with and without axial magnetic fields to measure the brightness of an extracted $1-2 \mathrm{kA}$, $1-1.5 \mathrm{MeV}$ electron beam will be described. The output beam of the High Brightness Test Stand as measured by one of these techniques is in excess of $2 \times 10^{5} \mathrm{amp} / \mathrm{cm}^{2} /$ steradian.

\footnotetext{
*Work performed jointly under the auspices of the U. S. Department of Energy by Lawrence Livermore National Laboratory under contract W-7405-ENG-48 and for the Department of Defense under Defense Advanced Research Projects Agency ARPA Order No. 4395 Amendment \#31, monitored by Naval Surface Weapons Center under document number N60921-B5-P0W0001; and SDIO/BMD-ATC MIPR \#W3-RPD-53-A127.

\section{DISCLAIMER}

\begin{abstract}
This report was prepared as an account of work sponsored by an agency of the United States Government. Neither the United States Government nor any agency thereof, nor any of their employees, makes any warranty, express or implied, or assumes any legal liability or responsibility for the accuracy, completeness, or usefulness of any information, apparatus, product, or process disclosed, or represents that its use would not infringe privately owned rights. Feference herein to any specific commercial product, process, or service by trade name, trademark, manufacturer, or otherwise coes not necessarily constitute or imply its endorsement, recommendation, or favoring by the United States Government or any agency there:- The views and opinions of authors expressed herein do not necessarily state or reflect those of the United States Government or any agency thereof.
\end{abstract}

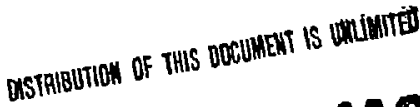




\section{INTRODUCTION}

Electron beams of very high brightness are required for free electron laser applications. A special High Brightness Test Stand (HBTS) has been constructed to study different cathode materials and electrode configurations in an attempt to develop a high brightness injector for the Advanced Test Accelerator (ATA) at the Lawrence Livermore National Laboratory.

\section{DEFINITIONS}

The definition of the normalized brightness $J_{n}$, used in this paper is given in Eq. (1) and is equivalent to $\pi^{2}$ multiplied by the density in four dimensional transverse trace space:

$$
J_{n}=\frac{\pi^{2}}{(\beta \gamma)^{2}} \frac{d^{4} I}{d V_{4}}
$$

Here $d_{4}$ is the differential volume element in the four-dimensional transverse trace space $\left(x, x^{\prime}, y, y^{\prime}\right)[1]$ where a prime denotes differentiation with respect to $z$, the coordinate along the beams' direction of propagation, and $d^{4} I$ is the element of current enclosed in that element of four volume. $\beta \gamma=\sqrt{\gamma^{2}-1}$ where $\gamma$ is the usual Lorentz factor.

For example, if the distribution in trace space is ellipsoidal with a boundary satisfying the equation $1-\left(x^{2}+y^{2}\right) / b^{2}-\left(x^{\prime 2}+y^{\prime 2}\right) / v^{2}=0$, then it is easily shown that $v_{4}=\pi^{2} E^{2} / 2$ where $E$ the edge emittance is $=b v$. If the trace space density is uniform then the normalized beam brightness in our 
definition is $J_{n}=2 I / E_{n}^{2}$ where $I$ is the total beam current and $E_{n}=\beta \gamma E$, the normalized edge emittance.

\section{EXPERIMENTAL DESCRIPTION}

A schematic of the HBTS [2] is shown in Fig. 1. Tha typical anode voltage for the test stand varies from 1.0 to $1.5 \mathrm{MV}$ and the extracted beam current ranges from a few hundred amperes up to over $1 \mathrm{kA}$ in a $50 \mathrm{nsec}$ pulse at a repetition rate of approximately 1 Hertz.

For the measurements described here the gun was configured as a pentode [3] as shown in Fig. 2. The cathode consisted of ordinary velvet cloth which produced electrons via field emission. Only elertrostatic focusing was employed in the anode-cathode gap although solenoidal focusing was used downstream of the anode.

Two widely separated small diameter apertures were used to diagnose the brightness of the extracted beam. Wall current monitors were positioned to measure tie beam current exiting the gun as well as the current surviving downstream of each of the two apertures. A diagram of the arrangement is shown in Fig. 3.

\section{MEASUREMENT THEORY}

An explanation of the brightness measuring method follows. Consider a magnetic fleld free pipe of radius $R_{p}$ and length $L$. If the beam entering 
It is desirable that the typical thermal angle of the beam be arger than that of the beam envelope so that the collimating system measures brightness and not the effects of beam convergence or divergence. Thus, we want $E / R_{b} \gg R^{\prime}$.

Now the maximum angle passed by the collimator is $2 R_{p} / L$ and this angle must be smaller than the typical thermal angle in the beam so that the system will collimate in $x^{\prime}-y^{\prime}$ space. Thus, $2 R_{p} / L<E / R_{b}$. Note that if $R_{b}$ becomes too large the pipe will collimate only in $x$ - y spare and hence will simply measure current density. Thus, the radius of the incident beam must satisfy the relation

$$
R_{p}<R_{b}<\frac{E L}{2 R_{p}}
$$

and

$$
R^{\prime} \ll E / R_{b}
$$

These relations may be written in terms of beam brightness and current through use of the approximate relation $J_{n}=2 I / E_{n}{ }^{2}$ to give

$$
R_{p}<R_{b}<\sqrt{\left(1 / 2 J_{n}\right)} \frac{L}{\beta Y R_{p}}
$$

and

$$
R^{\prime} \ll \sqrt{\left(2 I / J_{n}\right)} /\left(\beta Y R_{b}\right)
$$

In practice, a gated television camera views the entrance aperture to judge spot size while the wall current monitor downstream of the first aperture allows a qualitative check on the size of the beam. A short steering magnet 
is placed upstream of both apertures to compensate for any positioning or alignment errors of the system and to permit sampling of different portions of the beam (in $x-y$ space) at the entrance to the first aperture.

The collimating system used in the HBTS consisted of plates with $3 / 16$ in. diameter holes placed 15 inches apart. The anode voltage was nominally $1.25 \mathrm{MV}$ and the gun had an output current of nearly $1.2 \mathrm{kA}$. The waveforms of the incident beam current and voltage and the currents through both apertures are shown in Fig. 4. The current transmitted through the second aperture was 5 amperes yielding a normalized brightness of $2 \times 10^{5} \mathrm{amp} / \mathrm{cm}^{2} / \mathrm{steradian}$.

\section{MAGNETIC COLLIMATOR}

Another type of collimator employing a pipe emersed in a uniform solenoidal field may also be used to determine brightness. [5] In this system the particle orbits are assumed to be pure cyclotron orbits and the allowed volume [4] in trace space is $v_{c}=\pi^{2} k_{c}{ }^{2} R_{p}{ }^{4} / 6$. The current passed by this system will yield the brightness as

$$
J_{n}=\frac{6 I}{k_{0}^{2} R_{p}^{4}}
$$

where $k_{0}=e\left[3 / \mathrm{mc}^{2}\right.$. Note that with this type of collimator the calculated brightness is independent of the beam energy.

As with the field free collimator this system must also satisfy certain conditions in order to produce a valid measurement. The space charge 
requirement is the same as that given in $\mathrm{Eq} .(5)$. The condition on the angle of the beam envelope given by Eqs. (7) and (9) is also valid for the magnetic collimator. The maximum angle accepted by the magnetic collimator is $k_{c} R_{p}$ so that Eq. (6) becomes

$$
R_{p}<R_{b}<\frac{E}{k_{c} R_{p}}
$$

Another requirement for the magnetic collimator is that it be at least one cyclotron wavelength long so that all particle orbits may be fully "filtered." The magnetic collimator has been used on the Experimental Test Accelerator but has not yet been used on the HBTS.

\section{CONCLUSIONS}

In summary, two brightness measuring diagnostics have been described along with the required beam conditions necessary to insure their proper operation. The field free collimator was used to diagnose a normalized beam brightness of $2 \times 10^{5}$ on the HBTS. 


\section{HBTS}

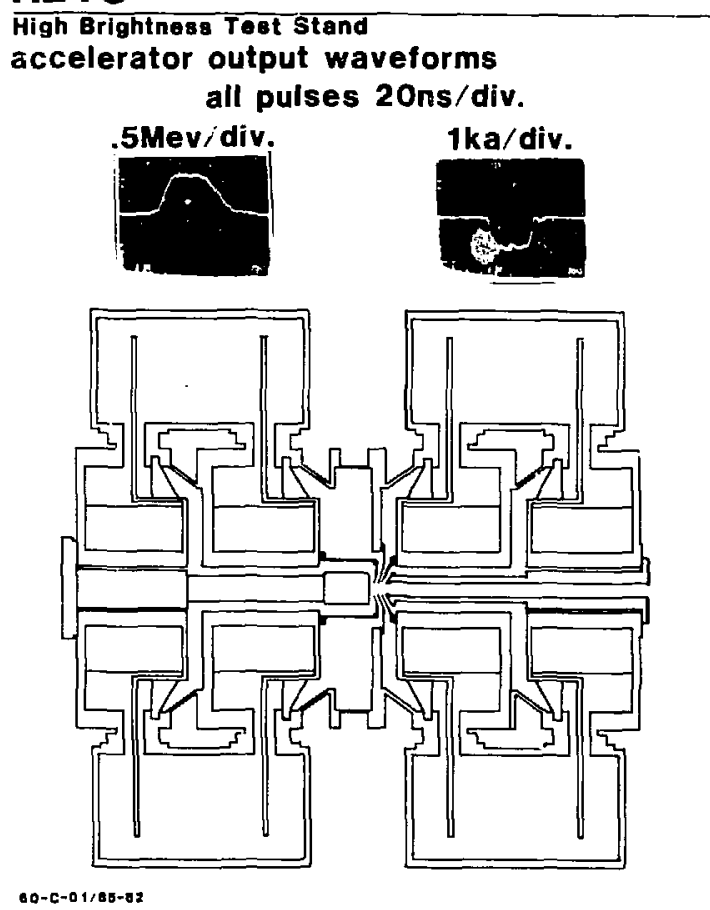

Fig. 1. Schematic of the High Brightness Test Stand showing the four induction accelerator modules that supply the power to four electrodes of the pentode structure. The gun is electrustatically focused and uses a field emission cathode (velvet cloth). 


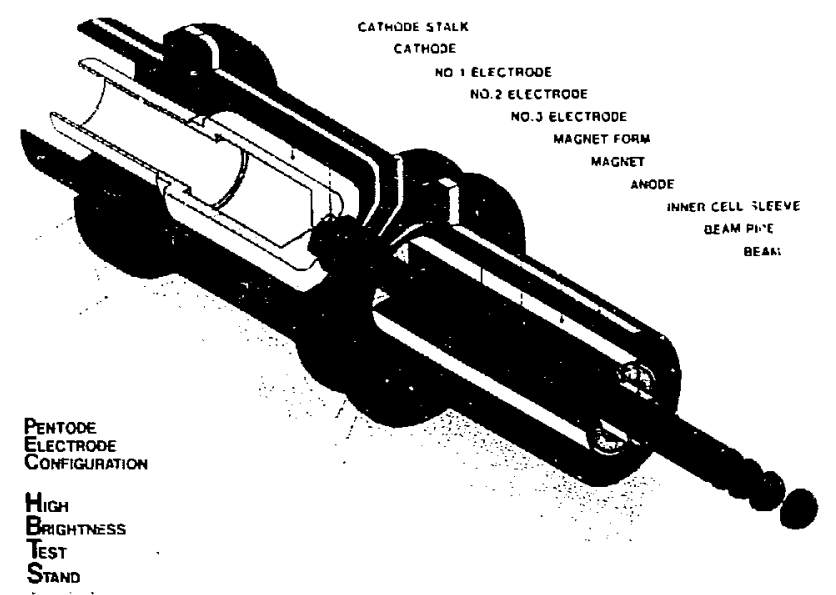

Fig. 2. Diagram of the pentode gun structure showing the cathode stalk, three intermediate electrodes and the anode. The voltage differences between all electrodes are equal in this configuration. Also shown is a solenoid used to focus the beam downstream of the anode hole.

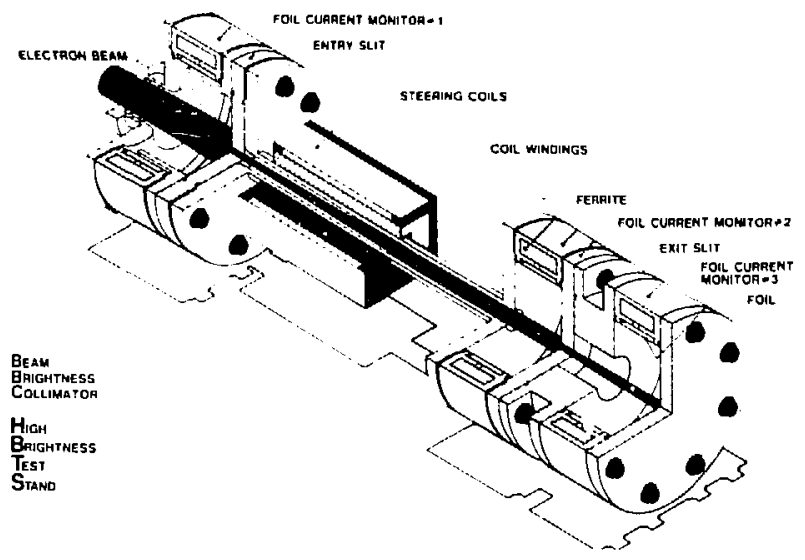

Fig. 3. Schematic of the field free collimator showing the two apertures with three wall current monitors which measure incident beam currents on the first and second apertures and current which emerges from the second aperture. Also shown is the inter-aperture steering coil. An additional steering coil, not shown, is upstream of the first aperture. 


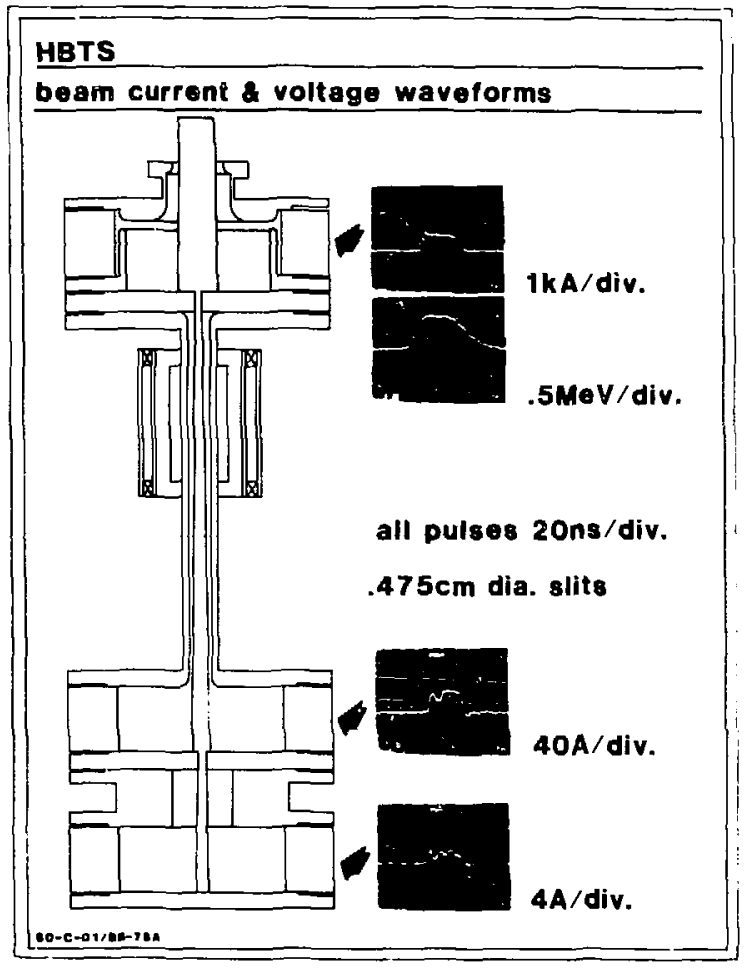

Fig. 4. Another schematic of the field free collimator system showing waveforms of the incident current and voltage as well as the current just upstream and downstream of the second aperture for the measurement described in the text. 


\section{REFERENCES}

[1] C. Lejeune and J. Aubert, "Emittance and Brightness: Definitions and Measurements," in Advances in Electronics and Electron Physics, Supplement 13A, edited by A. Septier. Academic Press, p. 174 (1980).

[2] D. L. Birx, "Technology of Magnetically Driven Accelerators, " invited paper K 4; 1985 Particle Accelerator Conf., Vancouver, BC, May 13-16, 1985.

[3] G. J. Caporaso, A. G. Cole and J. K. Boyd, "Analytical Methods of Electrode Design for a Relativistic Electron Gun," paper Y 34; 1985 Particle Accelerator Conf., Vancouver, BC, May 13-16, 1985.

[4] A. M. Sessler, private communication.

[5] A. C. Paul, A. M. Sessler, J. S. Wurtele, G. J. Caporaso and A. G. Cole, "A Variable Emittance Filter for the Electron Laser Facility." Proceedings of the 4 th Workshop on Free Electron Laser Devices, Rosario Resort, June 27 - July 1, 1983. 